\title{
Analysis of Incidence-Severity Relationships for Strawberry Powdery Mildew as Influenced by Cultivar, Cultivar Type, and Production Systems
}

O. Carisse and A. Lefebvre, Agriculture and Agri-Food Canada, St.-Jean-sur-Richelieu, QC J3B 3E6, Canada; and H. Van der Heyden, Linda Roberge, and Luc Brodeur, Compagnie de recherche Phytodata Inc., Sherrington, QC J01 2N0, Canada

\begin{abstract}
Carisse, O., Lefebvre, A., Van der Heyden, H., Roberge, L., and Brodeur, L. 2013. Analysis of incidence-severity relationships for strawberry powdery mildew as influenced by cultivar, cultivar type, and production systems. Plant Dis. 97:354-362.

The relationships between strawberry powdery mildew incidence (I) and severity $(\mathrm{S})$ were investigated for various cultivars, for Junebearing and day-neutral cultivars, and for production systems (openfield and plastic-tunnel) with the objective of deriving a simple relationship for predicting severity (proportion of leaf area diseased [PLAD]) from incidence (proportion of diseased leaves). Data were collected from 2006 to 2011 at 11 commercial and experimental sites, for a total of 2,326 observations $(n)$. For the cultivars grown in open fields, higher severity was observed on 'Seascape', with mean PLAD of $0.299(n=427)$; followed by 'Chambly', with $0.133(n=334)$; 'Cavendish', with $0.115(n=250)$; 'Darselect', with $0.111(n=321)$; and 'Jewel', with $0.105(n=276)$. In general, mean severity was higher when the strawberry plants were grown in plastic tunnels, with PLAD of $0.204,0.199$, and 0.181 for Chambly $(n=204)$, Darselect $(n=261)$, and Jewel $(n=253)$, respectively. A linear model based on complementary log-log transformation of I and S provided a good fit of the

from 0.82 to 0.96$)$. A covariance analysis indicated that the sampling year and site of sampling did not significantly influence the estimated slope of the I-S relationship, nor did the specific cultivar among the June-bearing ones, whereas the production system (open-field versus plastic-tunnel) and the cultivar type (June-bearing versus day-neutral) significantly influenced the estimated slope. From this analysis, we were able to develop three specific models for open-field-grown Junebearing cultivars $\left(R^{2}=0.90\right)$, for the open-field-grown day-neutral cultivar (Seascape, $R^{2}=0.91$ ), and for June-bearing cultivars grown in plastic tunnels $\left(R^{2}=0.92\right)$. From these results, it was concluded that strawberry powdery mildew leaf severity can be accurately estimated from incidence of diseased leaves. The I-S relationships developed in the present study may be used in making practical disease management decisions, especially for management programs that use information on disease level in the field to initiate fungicide spraying programs or to time the interval between sprays.
\end{abstract} data (coefficient of determination $\left[R^{2}\right]$ adjusted for degrees of freedom
Strawberry powdery mildew, caused by Podosphaera aphanis (Wallr.) U. Braun \& S. Takam (formerly Sphaerotheca macularis f. fragariae (Harz) Jacz), is present in a several of strawberry production areas worldwide $(3,4,19,29)$. Strawberry production in eastern Canada is a limited (7), albeit valuable, component of the fresh market and of the expanding market for locally produced food. Cultivated strawberry, Fragaria $\times$ ananassa (L) Duch., is the result of a cross between Fragaria chilonensis (L) Duch. and Fragaria $\times$ virginiana Duch. (14). Strawberry cultivars are generally classified based on their response to photoperiod. In June-bearing cultivars, buds are initiated during photoperiods of less than $14 \mathrm{~h} /$ day, whereas day-neutral cultivars are insensitive to photoperiod with respect to flower induction (6). One of the greatest challenges that strawberry producers face in eastern Canada is to provide the market with high-quality fruit over a long period of time, ideally from June to September. This has led to profound changes in production systems, with a shift from conventional production systems based on field-grown Junebearing cultivars to day-neutral cultivars and to strawberry plants grown under large plastic tunnels. Most evaluations of strawberry cultivars for their susceptibility to powdery mildew were conducted on cultivars not grown in Eastern Canada (22). However, the most common day-neutral strawberry cultivar, 'Seascape', was evaluated in California and was reported as moderately susceptible, although field observations suggest that this

Corresponding author: O. Carisse, E-mail: odile.carisse@ agr.gc.ca

Accepted for publication 6 September 2012.

http://dx.doi.org/10.1094/PDIS-05-12-0508-RE

This article is in the public domain and not copyrightable. It may be freely reprinted with customary crediting of the source. The American Phytopathological Society, 2013. cultivar is highly susceptible (23). Plastic tunnels provide optimal conditions for powdery mildew development (32). Hence, powdery mildew is now a major constraint to strawberry production in eastern Canada.

In June-bearing cultivars grown in fields, the onset of disease generally occurs after fruit harvest on regrowth of mown-off plants and, hence, does not cause direct yield losses during the current year. In 1969, Freeman and Pépin (9) reported that a severe epidemic of powdery mildew had no carry-over effect on yield in subsequent years. These results were further supported by Berrie and Burgess (2), who reported that, during the mild U.K. winters, strawberry plants that were severely mildewed in autumn showed reduced vigor, which was compensated for by the resumption of rapid growth in the following spring. It is not clear, however, whether severe epidemics occurring after harvest can cause a reduction in plant vigor and affect winter survival under the cold winters of eastern Canada. In day-neutral cultivars, direct yield losses are caused by infection of flowers and fruit, which are susceptible to infection in the early stages of development $(4,5)$. Severe infections can kill flowers and contaminate the pollen with conidia, resulting in poor pollination $(12,19)$. Infected green fruit may become hard and fail to ripen. Fruit infected at a later stage may be more prone to Botrytis cinerea infection and have a shortened shelf life $(23,25,26,30)$. In addition, the presence of white mycelium and conidia makes the fruit less attractive to pick-yourown customers, who often discard them. In Eastern Canada, losses that can be attributed to powdery mildew could be up to $30 \%$ (5).

Despite the lack of evidence that post-harvest mildew on Junebearing cultivars is harmful, growers generally carry out thorough and expensive fungicide schemes involving the application of sulfur and myclobutanil, a demethylation-inhibiting fungicide, at 7- to 10-day intervals. On day-neutral cultivars, growers are advised to apply fungicides at regular intervals from the emergence of the first leaves to harvest. In general, powdery mildew is more severe in August and September, which renders fungicide management diffi- 
cult in day-neutral cultivars because of the required preharvest intervals for most fungicides. In addition, recent reports on the development of resistance to demethylation-inhibiting fungicides in powdery mildew populations (28) point to the need for an integrated disease management approach, including the employment of host resistance and disease risk estimation.

In a recent study, the relationships between weather, airborne inoculum concentrations, foliar strawberry powdery mildew severity, and crop losses were analyzed using field data (5). The variable that most influenced crop losses was powdery mildew foliar severity. These results suggest that information on foliar powdery mildew must be considered when making disease management decisions. However, field assessment of strawberry powdery mildew is generally difficult, mainly because lesions typically occur as a diffuse colony on the abaxial leaf surface $(18,21,29)$. The ability to monitor strawberry powdery mildew incidence rather than severity would facilitate adoption of management programs which include scouting data.

The relationships between disease incidence and severity or intensity have been studied in many diseases at one or more levels of host spatial hierarchy $(11,16,20,24,33)$. For most of these diseases, it was possible to statistically describe these relationships and to develop models predicting severity from incidence at the same or a higher level of hierarchy (16). In general, the incidenceseverity relationship is influenced by factors such as cultivar susceptibility, fungicide spray program, time of disease assessment within the season, season, or location (24). Therefore, it is important to study the incidence-severity relationships under a broad range of conditions. Therefore, the specific objective of this study was twofold: first, to characterize statistically the relationship between strawberry powdery mildew incidence and severity; and, second, to determine the effect, if any, of sampling year, site, cultivar, cultivar type, and production system on the incidenceseverity relationship.

\section{Materials and Methods}

Sampling sites and disease assessment. Data were collected from 2006 to 2011 at the Agriculture and Agri-Food Canada experimental farm located in Frelighsburg and at 10 commercial strawberry farms located in several strawberry-production areas of the province of Quebec, Canada. Powdery mildew data were collected in fields planted with the June-bearing 'Cavendish', 'Chambly', 'Darselect', and 'Jewel' during the first or second year of production; in fields planted with the day-neutral Seascape; and in large plastic tunnels planted with the June-bearing Chambly, Darselect, and Jewel. Data were collected one to three times weekly from mid-June to mid-September for an average of 16, 20, and 56 samplings for the June-bearing grown in open fields, Junebearing grown in tunnels, and day-neutral cultivars, respectively. The data used for analysis are described in Table 1. At all sites, fungicides were applied to manage gray mold caused by $\mathrm{B}$. $\mathrm{ci}$ nerea. First sprays were applied when blossoms opened, repeated every 7 to 14 days depending on rains, and ended at harvest. Fungi- cides used included boscalid, pyraclostrobin+boscalide, fenhexamid, iprodione, and vinclozolin. Powdery mildew management practices varied from farm to farm. In general, on June-bearing cultivars, fungicides were not applied before renovation unless the disease was a problem the previous year; however, fungicides were applied after harvest in August or September. On June-bearing cultivars grown in plastic tunnels and on day-neutral cultivars, powdery mildew was managed with fungicides applied at regular intervals or based on scouting results. Fungicides used included lime sulfur and myclobutanil.
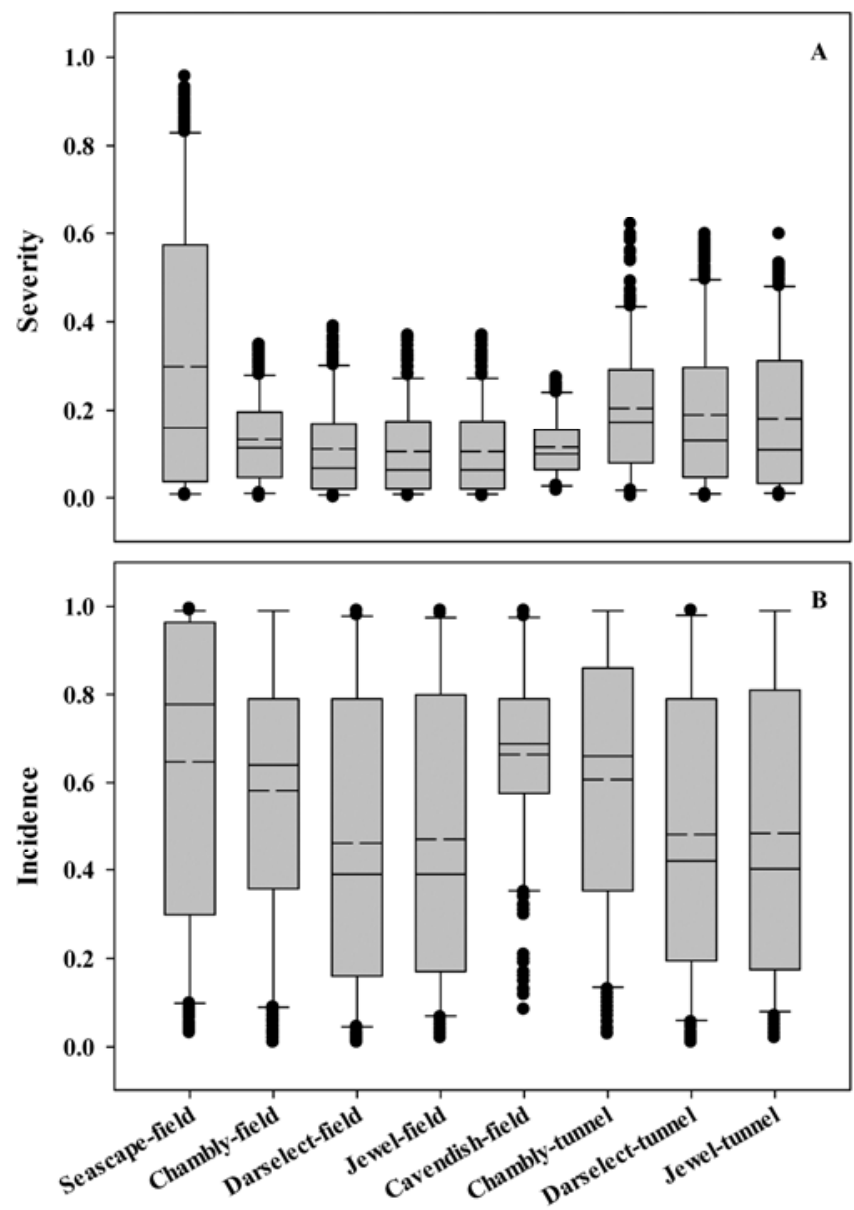

Cultivar-production systems

Fig. 1. Box plots summarizing the distribution of $\mathbf{A}$, severity and $\mathbf{B}$, incidence of strawberry powdery mildew. Solid and broken lines within the box represent the mean and median, respectively, while the top and bottom lines of the box represent the 75th and 25th percentiles of the data, respectively, and the dots represent outliers.

Table 1. Description of the data used to study the relationship between incidence and severity of strawberry powdery mildew caused by Podosphaerea aphanis

\begin{tabular}{|c|c|c|c|c|c|c|}
\hline \multirow[b]{2}{*}{ Cultivar } & \multicolumn{6}{|c|}{ Sampling year ${ }^{a}$} \\
\hline & 2006 & 2007 & 2008 & 2009 & 2010 & 2011 \\
\hline \multicolumn{7}{|l|}{ Open fields } \\
\hline 'Cavendish' & $56(4)$ & $130(7)$ & $73(4)$ & $72(4)$ & $13(1)$ & $14(1)$ \\
\hline ‘Chambly’ & $56(4)$ & $133(7)$ & $91(4)$ & $79(4)$ & $16(1)$ & $14(1)$ \\
\hline 'Darselect' & $34(2)$ & $54(3)$ & $122(6)$ & $116(6)$ & $34(2)$ & $14(1)$ \\
\hline 'Jewel' & $32(2)$ & $50(3)$ & $109(6)$ & $110(6)$ & $31(2)$ & $14(1)$ \\
\hline 'Seascape’ & $111(2)$ & $290(5)$ & $168(3)$ & $\ldots$ & $\ldots$ & $\ldots$ \\
\hline \multicolumn{7}{|l|}{ Large tunnels } \\
\hline Chambly & $\ldots$ & $62(3)$ & $76(3)$ & $101(3)$ & $\ldots$ & $\ldots$ \\
\hline Darselect & $20(1)$ & $39(2)$ & $106(5)$ & $101(5)$ & $19(1)$ & $\ldots$ \\
\hline Jewel & $10(1)$ & $35(2)$ & $119(6)$ & $95(5)$ & $18(1)$ & $\ldots$ \\
\hline
\end{tabular}

a Number of observations and fields surveyed (in parentheses). Each observation is the mean of 25 plants. 
Disease assessments were performed weekly on 25 strawberry plants selected randomly from each field. Foliar powdery mildew severity was assessed on the three youngest fully expanded leaves per plant as the proportion of leaf area diseased using a diagrammatic scale with 0.05 steps $(0,0.05,0.10,0.15 \ldots 1.00)$. Severity (S) was calculated as the mean severity (over all 25 plants). Powdery mildew incidence (I) was derived from the severity data by rating a leaf as diseased if severity was $>0$. Incidence was calculated as the proportion of diseased leaves. Only pairs of incidence and severity data with $\mathrm{I}>0$ were included in the analysis because incidenceseverity relationships can only be analyzed when disease is present (I >0) (24).

Analysis of the strawberry powdery mildew incidence-severity relationship. Data for each cultivar, cultivar type, and production system were first analyzed separately, then an analysis was conducted with pooled data. Incidence and severity data were transformed to complementary $\log -\log (\mathrm{CLL})$ as CLL(I) $=\ln [-\ln (1-$ I)] and $\operatorname{CLL}(S)=\ln [-\ln (1-S)]$, respectively. This model was selected based on the plots of severity as a function of incidence and because incidence and severity must lie between 0 and 1 (REF). Transformed data were modeled with linear ordinary leastsquares regression analyses as $C L L(S)=\beta_{0}+\beta_{1}[C L L(I)]$ (equation $1)$. This is an equation for a straight line with an intercept $\left(\beta_{0}\right)$ and a slope $\left(\beta_{1}\right)$. Several other models for incidence-severity relationships were evaluated based on previous usage in other pathosystems $(20,33)$. However, these models were not selected because their residual plots were non-random, or the shape of the curve for predicted severity versus incidence diverged from the shape of observed severity versus incidence. A one-sided $t$ test was used to determine whether the slope of equation 1 differed from 1 , based on the estimated $\beta_{1}$ and its standard error. Model fit was evaluated based on the coefficient of determination adjusted for degrees of freedom $\left(R_{\text {adj }}^{2}\right)$, squared correlation between back-transformed observed and predicted values $\left(R^{* 2}\right)$, and randomness of the residual plots. The analyses were performed with the GLM procedure of SAS (version 9.2; SAS Inc.).

Covariance analyses. A covariance analysis was conducted to measure the effect of the cultivar, cultivar type, production system, site, and year on the intercept $\left(\beta_{0}\right)$ and slope $\left(\beta_{1}\right)$ parameters of equation 1 . The purpose of this analysis was to determine whether these factors affected the incidence-severity relationship. The test of a factor is not an indication of whether the factor had a significant effect on powdery mildew severity but whether the factor influenced the incidence-severity relationship by influencing the intercept $\left(\beta_{0}\right)$ and slope $\left(\beta_{1}\right)$ parameters. Cultivars used were Chambly, Darselect, Jewel, Cavendish, and Seascape and the cultivar types were June-bearing and day-neutral. The production systems were open field and plastic tunnel, and this factor was tested only for the cultivars that were monitored in both production systems (Darselect, Chambly, and Jewel). The site and year factors were tested separately for each cultivar type and each production system (open-field June-bearing, open-field day-neutral, and plas-
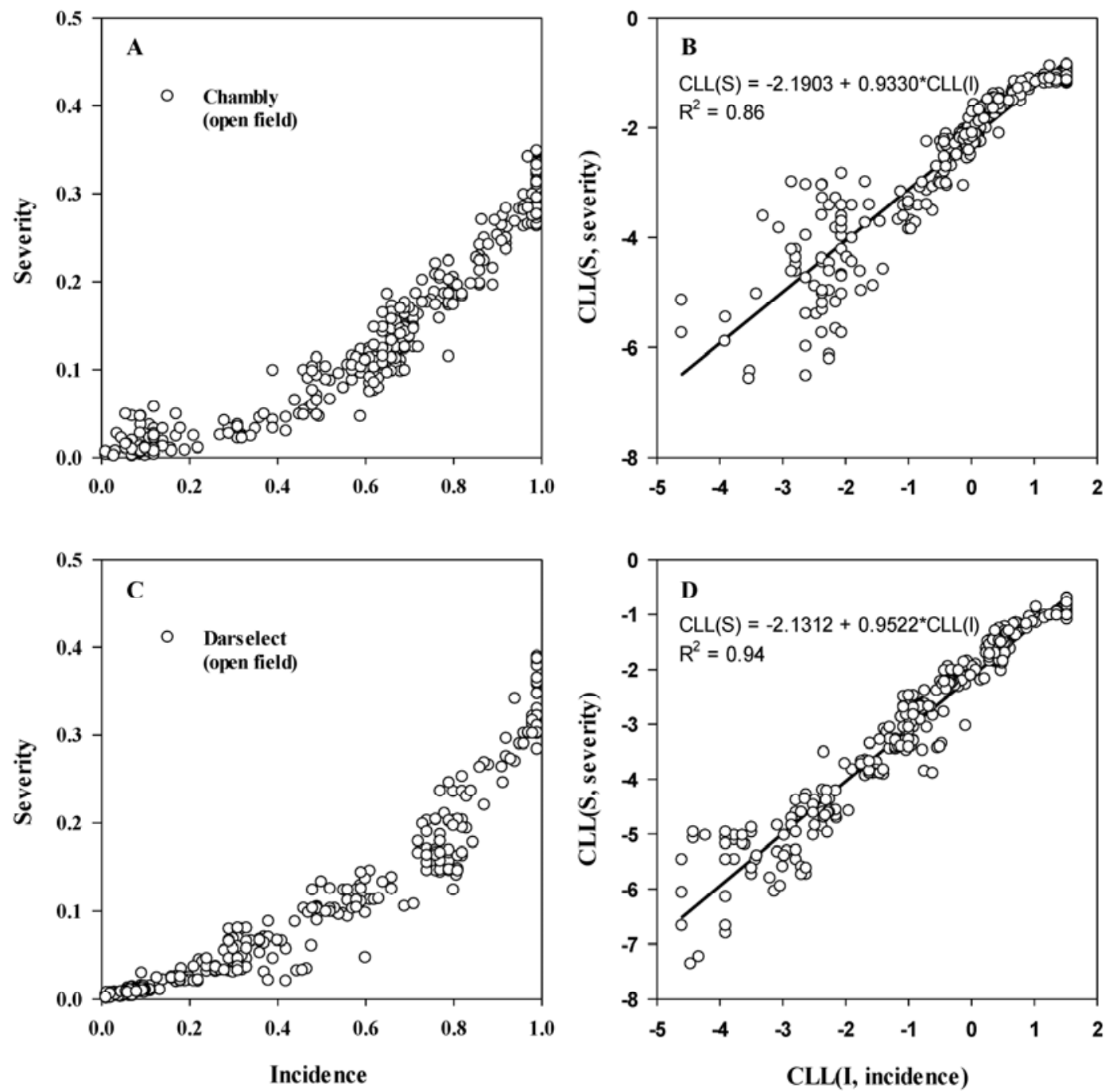

Fig. 2. Relationship between incidence and severity of strawberry powdery mildew for $\mathbf{A}$ and $\mathbf{C}$, untransformed and $\mathbf{B}$ and $\mathbf{D}$, complementary log-log (CLL)-transformed data for the June-bearing $\mathbf{A}$ and $\mathbf{B}$, 'Chambly' and $\mathbf{C}$ and $\mathbf{D}$, 'Darselect' grown in open fields. Each point represents the mean value from a sample of 75 leaves $(25$ plants $\times 3$ leaves per plant). Solid lines represent the predicted values on a CLL scale. 
tic-tunnel June-bearing). The covariance analysis was performed using the GLM procedure of SAS (version 9.2; SAS Inc.).

\section{Results}

The severity of strawberry mildew varied with cultivars and production systems. Under field conditions, the highest severity was observed for Seascape, which had mean severity of 0.299 . Lower but similar powdery mildew severity values were observed for the other cultivars, with severity of $0.133,0.111,0.105$, and 0.115 for Chambly, Darselect, Jewel, and Cavendish, respectively (Fig. 1). Seascape, Cavendish, and Jewel had similar mean incidence values of $0.647,0.664$, and 0.578 , respectively (Fig 1). Powdery mildew incidence was lower for Chambly and Darselect, with incidence of 0.472 and 0.463 , respectively. More variation in powdery mildew severity was observed when the strawberry plants were produced under plastic tunnels. Under tunnels, the mean disease severity values for Chambly, Darselect, and Jewel were 0.204, 0.190, and 0.181 , respectively. Under plastic tunnels, the mean powdery mildew incidence values for Chambly, Darselect, and Jewel were $0.607,0.485$, and 0.477 , respectively. The distribution of powdery mildew severity and incidence across cultivars and production systems is illustrated in Figure 1.

The relationship between CLL-transformed powdery mildew severity and incidence was linear (Figs. 2-6). For all cultivars, cultivar types, and production systems, these regressions explained a large proportion of the variation in transformed severity, with co- efficients of determination ranging from 0.82 to 0.96 (Table 2). For all cultivars, cultivar types, and production systems, the parameter estimates for equation $1\left(\beta_{0}\right.$ and $\left.\beta_{1}\right)$ were highly significant (Table $2)$. All $F$ values were significant $(P<0.001)$, meaning that $\beta_{1}$ differed from 0 . Estimated intercepts $\left(\beta_{0}\right)$ ranged from -2.4307 to -1.8661 for the strawberry plants grown under field conditions and from -1.7987 to -1.5539 for the strawberry plants grown under plastic tunnels (Table 2). For the June-bearing cultivars grown in open fields, the slope parameters $\left(\beta_{1}\right)$ varied between 0.9064 and 0.9522 , whereas the range of values was 1.0112 to 1.0153 for the same cultivars grown under large tunnels. The estimate of the slope parameter for the day-neutral cultivar grown in open fields (1.2674) was similar to the estimate for June-bearing cultivars grown in plastic tunnels (Table 2). When all data were pooled, the estimate of the slope parameter was 1.0115 (Table 2). The estimate of the slope parameters for the June-bearing cultivars taken alone was 0.9182, which was lower than for the day-neutral Seascape $\left(\beta_{1}=1.2674\right)$. When data for the June-bearing Darselect, Chambly, and Jewel were pooled, the estimate of the slope parameter was lower for the open-field production system compared with plastic tunnels, with estimates of 0.9358 and 1.0021 , respectively (Table 2).

Based on the analysis of covariance, for the June-bearing cultivars grown in open fields, the cultivar, site, and year factors had a significant effect on the intercept $(P<0.0001, P=0.0002$, and $P<$ 0.0015 , respectively) but no significant effect on the slope param-
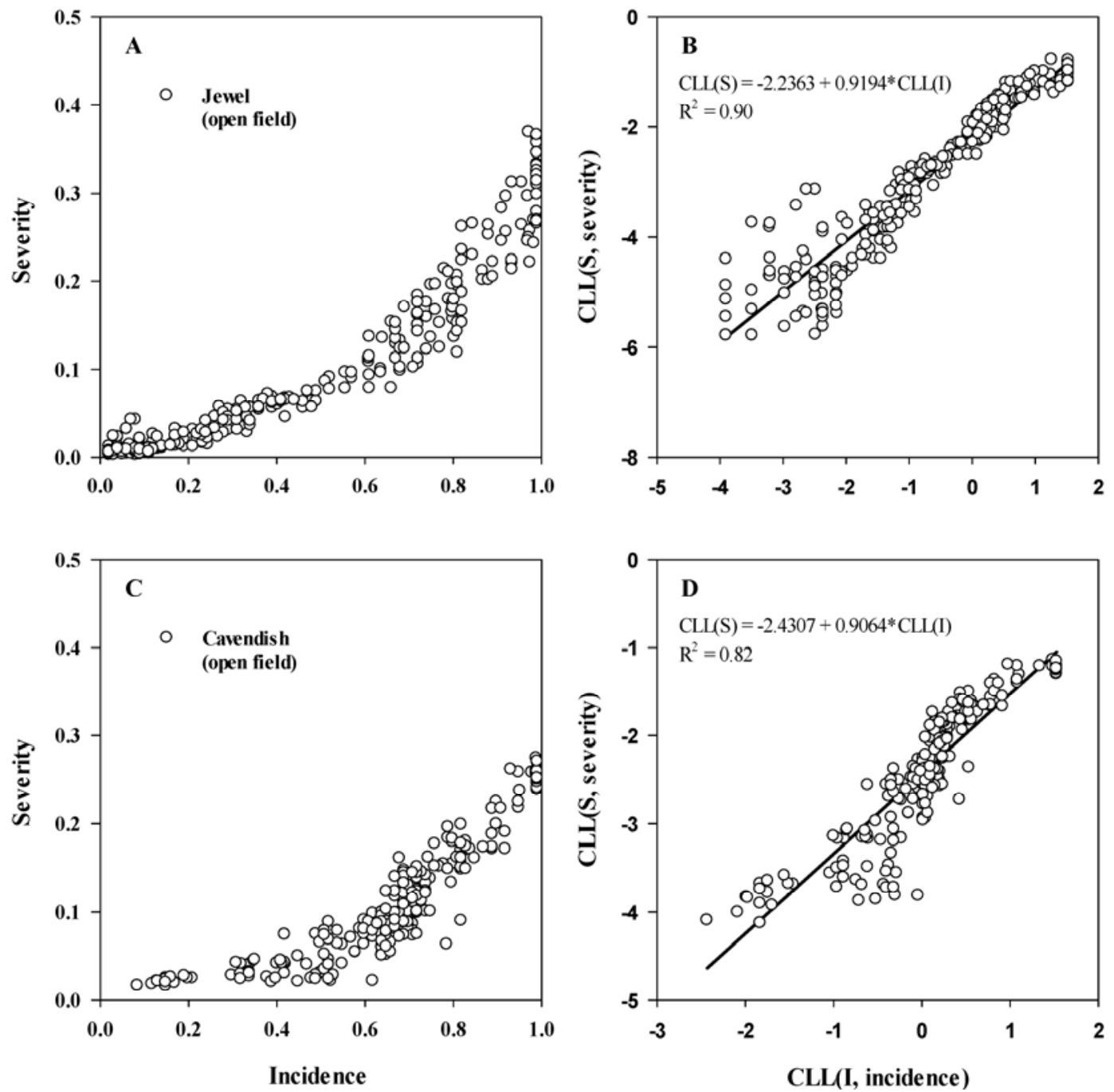

Fig. 3. Relationship between incidence and severity of strawberry powdery mildew for $\mathbf{A}$ and $\mathbf{C}$, untransformed and $\mathbf{B}$ and $\mathbf{D}$, complementary log-log (CLL)-transformed data for the June-bearing A and B, 'Jewel' and C and D, 'Cavendish' grown in open fields. Each point represents the mean value from a sample of 75 leaves ( 25 plants $\times 3$ leaves per plant). Solid lines represent the predicted values on a CLL scale. 
eter $(P=0.4136, P=0.3156$, and $P=0.1698$, respectively) of the CLL(I)-CLL(S) relationship. Despite the significant effect of the cultivar, site, and year factors on the intercept, the ranges of estimated intercepts (back-transformed values) were small (0.84 to $0.112,0.96$ to 0.105 , and 0.094 to 0.107 for cultivar, site, and year, respectively). For the day-neutral Seascape grown in open fields, the site and year factors had a significant effect on the intercept $(P$ $=0.0027$ and $P<0.0002$, respectively) but no significant effect on the slope parameter ( $P=0.0932$ and $P=0.2347$, respectively) of the CLL(I)-CLL(S) relationship. The ranges of estimated intercepts (back-transformed values) were 0.127 to 0.36 and 0.124 to 0.140 for site and year, respectively. Similarly, for the June-bearing strawberry plants grown in plastic tunnels, the cultivar, site, and year factors had a significant effect on the intercept $(P<0.0001, P$ $=0.0003$, and $P<0.0089$, respectively) but no significant effect on the slope parameter $(P=0.4126, P=0.3135$, and $P=0.3371$, respectively) of the CLL(I)-CLL(S) relationship. Despite the significant effect of the cultivar, site, and year factors on the intercept, the range of estimated intercepts (back-transformed values) were small ( 0.153 to $0.171,0.147$ to 0.164 , and 0.153 to 0.169 for cultivar, site, and year, respectively). For the strawberry plants grown in open fields, cultivar type (day-neutral versus June-bearing) had a significant effect on the intercept parameter $(P=0.0007$; backtransformed intercept values of 0.101 and 0.113 for June-bearing and day-neutral, respectively) and on the slope parameter $(P<$ 0.0001) of the CLL(I)-CLL(S) relationship (Table 2). For the strawberry cultivars Darselect, Chambly and Jewel, the production system (open field versus large tunnel) had a significant effect on both the intercept $(P<0.0001$, back-transformed intercept values of 0.106 and 0.171 , for open field and large tunnel, respectively) and the slope parameter $(P<0.0001$, back-transformed slope values of 0.101 and 0.113 for open field and large tunnel, respectively) of the CLL(I)-CLL(S) relationship. Based on these analyses, three specific models were developed: one for the Junebearing cultivars grown in open fields $\left(\beta_{0}=-2.2449, \beta_{1}=0.9192\right.$, $R^{2}$ adj $=0.90$ ), one for the day-neutral Seascape grown in open fields $\left(\beta_{0}=-1.8661, \beta_{1}=1.2674, R_{\text {adj }}^{2}=0.92\right)$, and one for the Junebearing cultivars grown in plastic tunnels $\left(\beta_{0}=-1.6734, \beta_{1}=\right.$ $1.0021, R_{\text {adj }}^{2}=0.92$ ).

\section{Discussion}

Although powdery mildew has been recognized as an important strawberry disease for more than a century (27), there is little information on its epidemiology $(1,8,10,13,15,17,29,31)$, mainly because, until recently, the disease was managed mostly through the use of host genetic resistance $(22,23)$. However, shifts in production systems and strawberry types, as well as increased fungicide resistance, have led to powdery mildew outbreaks in several strawberry production areas (28). Disease quantification is essential for epidemiological studies, surveys, and management decisions. However, field assessment of strawberry powdery mildew severity is generally difficult. Powdery mildew typically occurs as patches
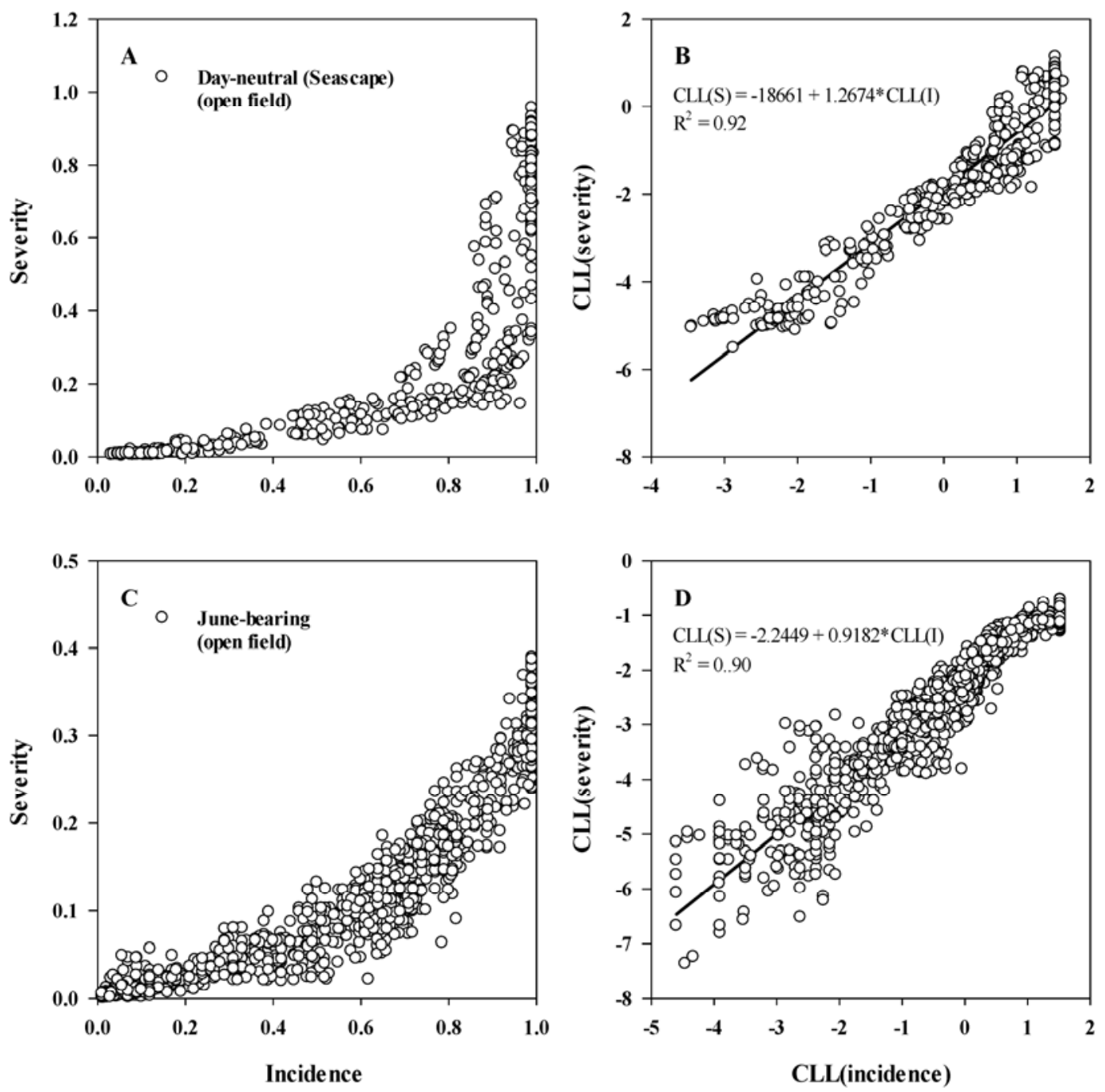

Fig. 4. Relationship between incidence and severity of strawberry powdery mildew for $\mathbf{A}$ and $\mathbf{C}$, untransformed and $\mathbf{B}$ and $\mathbf{D}$, complementary log-log (CLL)-transformed for the day-neutral A and B, Seascape and C and D, the June-bearing 'Chambly', 'Darselect', 'Jewel', and 'Cavendish' grown in open fields. Each point represents the mean value from a sample of 75 leaves ( 25 plants $\times 3$ leaves per plant). Solid lines represent the predicted values on a CLL scale. 
or diffuse colonies on the underside of the leaves, making assessment of severity challenging (19). Hence, field estimation of strawberry powdery mildew severity is time consuming and requires well-trained personnel, which may limit the adoption of integrated management programs that require information on disease levels in fields (5). The estimation of disease severity from the incidence level should facilitate powdery mildew quantification considerably because it is easier to assess incidence than severity.

The main objective of this study was to establish a reliable statistical model describing the incidence-severity relationship of strawberry powdery mildew. The approach used was to transform both the incidence data and the severity data. The complementary $\log -\log (20,24)$ transformation was found to be the most suitable transformation method. A highly significant relationship between powdery mildew incidence and severity was observed for all data sets. Regardless of the variation in severity at high incidence values, the model based on the CLL transformation of incidence and severity data provided a good fit for all data sets, explaining between 82 and $96 \%$ of the variation in severity on a CLL scale. The squared correlations $\left(R^{* 2}\right)$ between observed and predicted severity
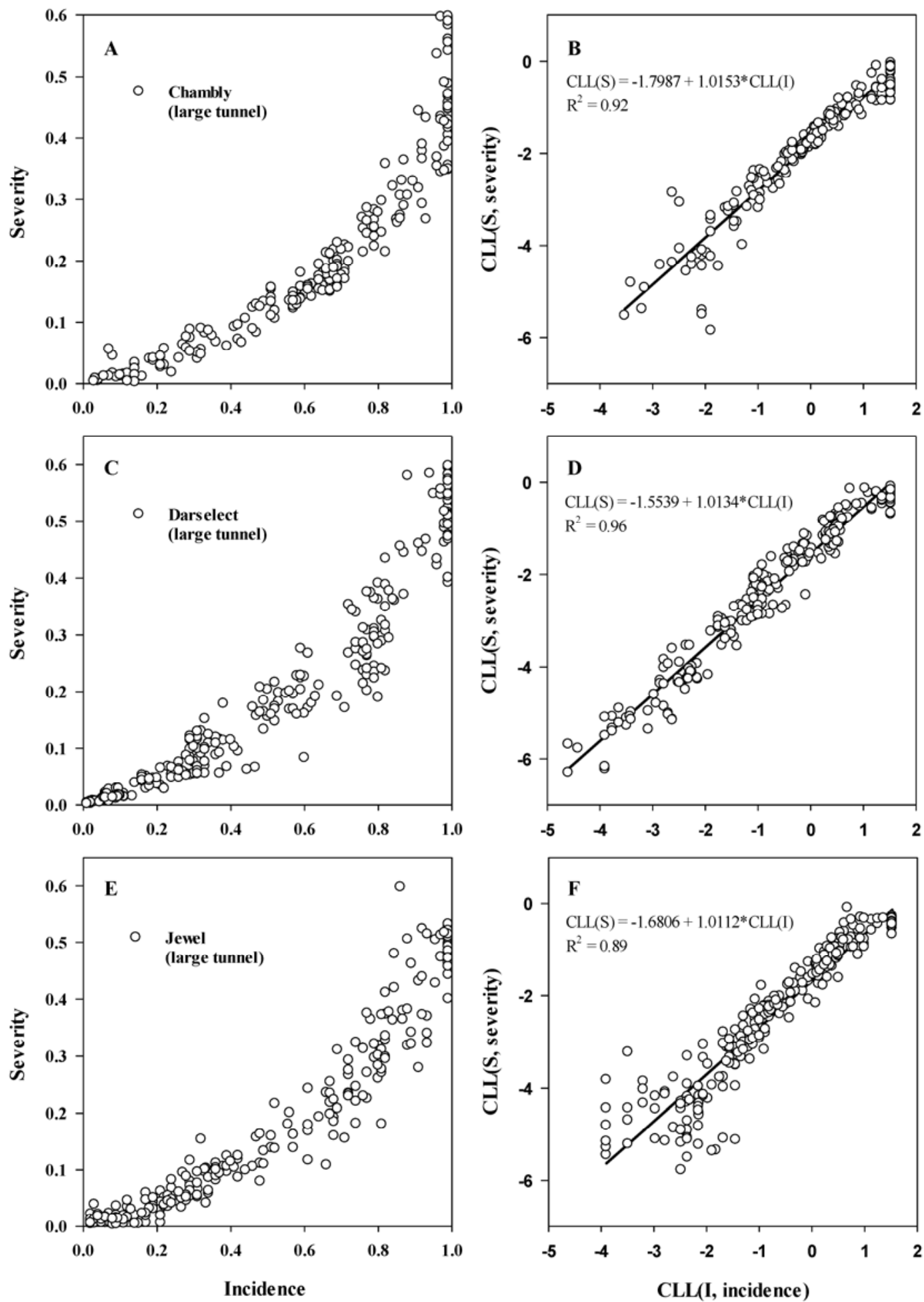

Fig. 5. Relationship between incidence and severity of strawberry powdery mildew for A, C, and E, untransformed and B, D, and F, complementary log-log (CLL)-transformed data for the June-bearing A and B, 'Chambly'; C and D, 'Darselect'; and E and F, 'Jewel' grown in plastic tunnels. Each point represents the mean value from a sample of 75 leaves ( 25 plants $\times 3$ leaves per plant). Solid lines represent the predicted values on a CLL scale. 

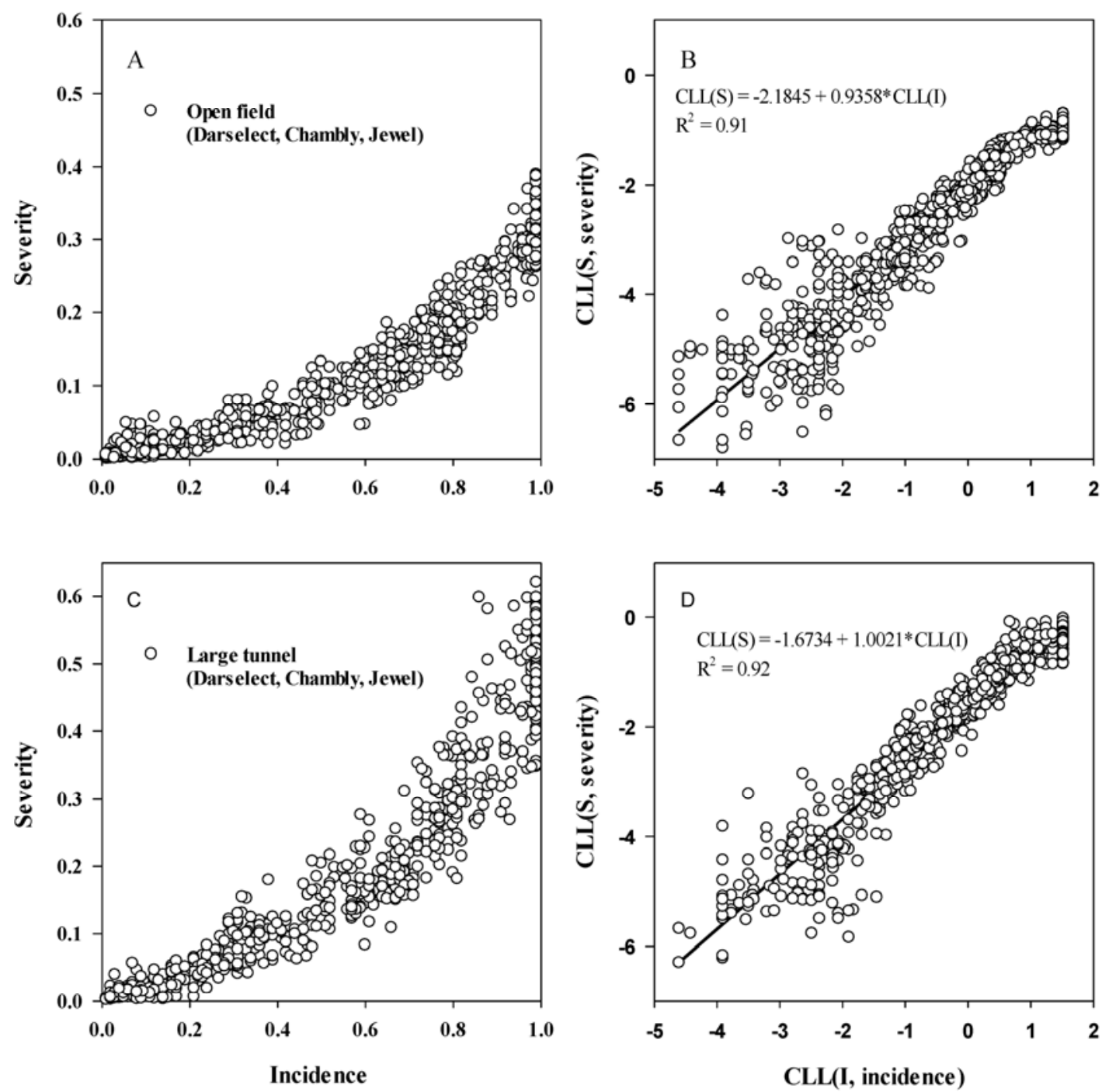

Fig. 6. Relationship between incidence and severity of strawberry powdery mildew for $\mathbf{A}$ and $\mathbf{C}$, untransformed and $\mathbf{B}$ and $\mathbf{D}$, complementary log-log (CLL)-transformed for the June-bearing 'Chambly', 'Darselect', and 'Jewel' grown in A and B, open fields and $\mathbf{C}$ and $\mathbf{D}$, plastic tunnels. Each point represents the mean value from a sample of 75 leaves ( 25 plants $\times 3$ leaves per plant). Solid lines represent the predicted values on a CLL scale.

ranged from 0.84 to 0.94 . Several authors who studied incidenceseverity relationships for other diseases $(20,24)$ reported that several factors, including host resistance, season, and site, may influence this relationship. In this study, the influence of cultivars grown in open fields, cultivar types (June-bearing versus day-neutral), production systems (open-field versus plastic-tunnel), site, and year of sampling was investigated. Overall, the site and the year of sampling did not influence the incidence-severity relationship for strawberry powdery mildew (no significant interaction with the slope parameter of the linear model relating CLL(I) to CLL(S)). Similarly, in this study, the specific cultivar used, whether Cavendish, Chambly, Darselect, or Jewel, did not influence the incidence-severity relationship. However, under openfield conditions, the cultivar type significantly influenced this relationship, as shown by the much higher slope for the linear model relating CLL(I) to CLL(S) obtained for the day-neutral Seascape (1.2674) compared with the June-bearing cultivars (0.9182). Seascape is generally considered to be highly susceptible to powdery mildew, whereas the other cultivars are considered to be moderately susceptible $(4,22,23)$. This may explain why, for a given incidence, higher severity was observed for Seascape. For example, at an incidence level of 0.5 (50\% of leaves diseased), the predicted severity for a June-bearing cultivar was $15.4 \%$ while the predicted severity for the day-neutral Seascape was $25.3 \%$. Similarly, the production system significantly influenced the I-S relationship. When the June-bearing Chambly, Darselect, and Jewel were grown in open fields, the slope of the CLL(I)-CLL(S) model was 0.9358 , compared with 1.002 when the same cultivars were grown in plastic tunnels. At an incidence of 0.5 , the predicted severity was $16.4 \%$ for the cultivars grown in open fields and $26.6 \%$ for the same cultivars grown in large tunnels.

In addition to the practical applications that can be developed from incidence-severity relationships, knowledge of the functional relationship between incidence and severity is important, because it improves understanding of the epidemiology of the disease. In this study, for example, the I-S relationship was investigated in three June-bearing cultivars (Chambly, Darselect, and Jewel) grown in open fields or in plastic tunnels. Under open-field conditions, severity increased with increasing incidence at a lower rate than when these cultivars were grown in plastic tunnels (Fig. 6), as shown by maximum severity values of 38.97 and $62.03 \%$ for open fields and plastic tunnels, respectively. These results suggest that the conditions in plastic tunnels favor auto-infection, which is reflected in increased severity for the same level of incidence rather than disease spread expressed by increased incidence for the same level of severity. Spore dispersal and strawberry powdery mildew gradients were studied in plastic tunnels and glasshouses in France (31). The authors reported that spore dispersal occurred mainly within $1.20 \mathrm{~m}$ from the source and that spore dispersal was much greater in plastic tunnels than in glasshouses, most likely due to the higher wind speed in tunnels compared with glasshouses. In the present study, wind speed was not measured but it is reasonable to 
Table 2. Summary of the regression analyses of the relationship between complementary log-log transformation of strawberry powdery mildew incidence and severity of strawberry powdery mildew caused by Podosphaerea aphanis

\begin{tabular}{|c|c|c|c|c|c|c|c|}
\hline \multirow[b]{2}{*}{ Cultivar ${ }^{b}$} & \multirow[b]{2}{*}{$\mathrm{Obs}^{\mathrm{c}}$} & \multicolumn{6}{|c|}{ Statistics $^{\mathbf{a}}$} \\
\hline & & $\beta_{0}(\mathrm{se})$ & $\beta_{1}(s e)^{d}$ & $R_{\text {adj }}^{2}$ & MSE & $F$ value & $R^{* 2}$ \\
\hline \multicolumn{8}{|l|}{ Open fields } \\
\hline 'Cavendish' & 250 & $-2.4307(0.0207)$ & $0.9064 *(0.0271)$ & 0.818 & 0.1043 & $1,118.10$ & 0.844 \\
\hline ‘Chambly’ & 334 & $-2.1903(0.0272)$ & $0.9330 *(0.0205)$ & 0.862 & 0.2364 & $2,074.09$ & 0.894 \\
\hline 'Darselect' & 321 & $-2.1312(0.0235)$ & $0.9522 *(0.0134)$ & 0.940 & 0.1402 & $5,044.98$ & 0.942 \\
\hline 'Jewel' & 276 & $-2.2363(0.0287)$ & $0.9194 *(0.0181)$ & 0.904 & 0.1842 & $2,580.51$ & 0.934 \\
\hline 'Seascape' & 427 & $-1.8661(0.0259)$ & $1.2674 *(0.0164)$ & 0.916 & 0.2876 & $4,627.76$ & 0.836 \\
\hline \multicolumn{8}{|l|}{ Plastic tunnels } \\
\hline Chambly & 204 & $-1.7987(0.0249)$ & $1.0153(0.0153)$ & 0.919 & 0.1255 & $2,303.55$ & 0.914 \\
\hline Darselect & 261 & $-1.5539(0.0219)$ & $1.0134(0.0134)$ & 0.956 & 0.1032 & $5,708.63$ & 0.921 \\
\hline Jewel & 253 & $-1.6806(0.0342)$ & $1.0112(0.0220)$ & 0.893 & 0.2467 & $2,111.42$ & 0.878 \\
\hline \multicolumn{8}{|l|}{ Pooled data } \\
\hline All & 2,326 & $-1.9764(0.0115)$ & $1.0115(0.0079)$ & 0.874 & 0.2857 & $1,6152.9$ & 0.872 \\
\hline June-bearing & 1,181 & $-2.2449(0.0129)$ & $0.9182 *(0.0091)$ & 0.897 & 0.1803 & $1,0267.3$ & 0.898 \\
\hline Open field & 931 & $-2.1845(0.0153)$ & $0.9358 *(0.0098)$ & 0.907 & 0.1884 & $9,101.86$ & 0.922 \\
\hline Plastic tunnel & 718 & $-1.6734(0.0163)$ & $1.0021(0.0109)$ & 0.921 & 0.1686 & $8,379.71$ & 0.906 \\
\hline
\end{tabular}

${ }^{a}$ Estimates of the intercept $\left(\beta_{0}\right)$ and slope $\left(\beta_{1}\right)$ of the regression lines, se is the standard error of the estimate, $R^{2}$ adj is the adjusted coefficient of determination, MSE is the mean square error, $F$ value is the $F$ statistic from the regression analysis of variance, and $R^{* 2}$ is the squared correlation between back-transformed observed and predicted values.

${ }^{\mathrm{b}}$ Factors used to group the observations. All, June-bearing, open field, and large tunnel included all observations; only observations for June-bearing cultivars grown in open field; observations for Darselect, Chambly, and Jewel grown in open field; and observations for Darselect, Chambly, and Jewel grown in large tunnel, respectively.

${ }^{c}$ Number of observations used in the regression analysis (excluding observations with severity and incidence equal to zero).

d Asterisks $(*)$ indicate that the slope is significantly different from 1 based on a two-sided $t$ test at the 0.05 confidence level.

assume that it was lower in the plastic tunnels than in the open fields, and that this favored within-plant infection (3).

Considering the influence of cultivar type and production system, three specific models were developed to predict strawberry powdery mildew severity in June-bearing cultivars grown in open fields or in plastic tunnels and for a day-neutral cultivar grown in open fields. To ensure the robustness of these predictive models, data were collected under a large range of conditions; however, field validation is likely required before these models can be used in other strawberry production areas. Nevertheless, the results show that strawberry powdery mildew severity can be estimated by counting the number of diseased leaves.

\section{Acknowledgments}

This work was financially supported by Agriculture and Agri-Food Canada. The contribution of H. Van der Heyden, L. Roberge, and L. Brodeur to this work was supported by the Compagnie de Recherche Phytodata Inc. We thank all the summer students and the scouts from the PRISME consortium for their technical assistance.

\section{Literature Cited}

1. Amsalem, L., Freeman, S., Rav-David, D., Nitzani, Y., Sztejnberg, A., Pertot, I., and Elad, Y. 2006. Effect of climatic factors on powdery mildew caused by Sphaerotheca macularis f. sp. fragariae on strawberry. Eur. J. Plant Pathol. 114:283-292.

2. Berrie, A. M., and Burgess, C. M. 1997. The effect of post-harvest epidemics of powdery mildew on yield and growth of strawberry cv. Elsanta. Proc. Third Strawberry Symp. Acta Hortic. 439:791-798.

3. Blanco, C., Santos, B., de los, Barrau, C., Arroyo, F. T., Porras, M., and Romero, F. 2004. Relationship among concentrations of Sphaerotheca macularis conidia in the air, environmental conditions, and the incidence of powdery mildew in strawberry. Plant Dis. 88:878-881.

4. Carisse, O., and Bouchard, J. 2010. Age-related susceptibility of strawberry leaves and berries to infection by Podosphaera aphanis. Crop Prot. 29:969978.

5. Carisse, O. Morissette-Thomas, V., Van der Heyden, H., Roberge, L., and Brodeur, L. 2012. Analysis of the relationships between weather, airborne inoculum of Podosphaera aphanis, powdery mildew foliar severity and strawberry yield losses. (Abstr.) Canadian Society of Phytopathology.

6. Darnell, R. L., Cantliffe, D. J., Kirschbaum, D. S., and Chandler, C. K. 2003. The physiology of flowering in strawberry. Hortic. Rev. 28:325-349.

7. FAOSTAT. FAO. http://faostat.fao.org/site/339/default.aspx

8. Farooq, M., Dodgson, J., and Hall, A. 2007. Examination of the morphology of Podosphaera aphanis cleistothecia and their role in over wintering of the fungus. Asp. Appl. Biol. 83:55-58.

9. Freeman, J. A., and Pepin, H. S. 1969. Effect of postharvest infection of powdery mildew on yield of the strawberry cultivar Northwest. Can. Plant Dis. Surv. 49:139.
10. Gadoury, D. M., Asalf, B., Heidenreich, M. C., Herrero, M. L., Welser, M. J., Seem, R. C., Tronsmo, A. M., and Stensvand, A. 2010. Initiation, development, and survival of cleistothecia of Podosphaera aphanis and their role in the epidemiology of strawberry powdery mildew. Phytopathology 100:246-251.

11. Gent, D. H., Farnsworth, J. L., and Johnson, D. A. 2012. Spatial analysis and incidence-density relationships for downy mildew on hop. Plant Pathol. 61:37-47.

12. Gooding, H. J., McNicol, R. J., and MacIntyre, D. 1981. Methods of screening strawberries for resistance to Sphaerotheca macularis (Wall ex Frier) and Phytophthora cactorum (Leb. And Cohn). J. Hortic. Sci. 56:239-245.

13. Gourley, C. O. 1979. Cleistothecia of Sphaerotheca macularis on strawberry leaves in Nova Scotia. Can. Plant Dis. Surv. 59:80.

14. Hancock, J. F. 1999. Strawberries. CABI Publishing, New York

15. Howard, C. M., and Albregts, E. E. 1982. Cleistothecia of Sphaerotheca macularis on strawberry plants in Florida. Plant Dis. 66:261-262.

16. Hughes, G., McRoberts, N., Madden, L. V., and Gottwald, T. R. 1997. Relationships between disease incidence at two levels in a spatial hierarchy. Phytopathology 87:542-550.

17. Jhooty, J. S., and McKeen, W. E. 1962. The perfect stage of Sphaerotheca macularis on strawberry plants. Plant Dis. Rep. 46:218-219.

18. Jhooty, J. S., and McKeen, W. E. 1965. Studies on powdery mildew of strawberry caused by Sphaerotheca macularis. Phytopathology 55:281-285.

19. Maas, J. L. 1998. Compendium of Strawberry Diseases, second ed. American Phytopathological Society, St Paul, MN.

20. McRoberts, N., Hughes, G., and Madden, L. V. 2003. The theoretical basis and practical application of relationships between different disease intensity measurements in plants. Ann. Appl. Biol. 142:191-211

21. Miller, T. C., Gubler, W. D., Geng, S., and Rizzo, D. M. 2003. Effects of temperature and water vapor pressure on conidial germination and lesion expansion of Sphaerotheca macularis f. sp. fragariae. Plant Dis. 87:484492.

22. Nelson, M. D., Gubler, W. D., Shaw, D. V. 1995. Inheritance of powdery mildew resistance in greenhouse-grown versus field-grown California strawberry progenies. Phytopathology 85:421-424.

23. Nelson, M. D., Gubler, W. D., Shaw, D. V. 1996. Relative resistance of 47 strawberry cultivars to powdery mildew in California greenhouse and field environments. Plant Dis. 80:326-328.

24. Paul, P. A., El-Allaf, S. M., Lipps, P. E., and Madden, L. V. 2005. Relationships between incidence and severity of Fusarium head blight on winter wheat in Ohio. Phytopathology 95:1049-1060.

25. Peries, O. S. 1962. Studies on strawberry mildew, caused by Sphaerotheca macularis (Wallr. ex. Fries) Jaczewski. I. Biology of the fungus. Ann. Appl. Biol. 50:211-224

26. Peries, O. S. 1962. Studies on strawberry mildew, caused by Sphaerotheca macularis (Wallr. Ex. Fries) Jaczewski. II. Host-parasite relationships on foliage of strawberry varieties. Ann. Appl. Biol. 50:225-233.

27. Salmon, E. S. 1900. The strawberry mildew. J. R. Hortic. Soc. 25:132-138.

28. Sombardier, A., Dufour, M. C., Blancard, D., and Corio-Costeta, M. F. 2010. Sensitivity of Podosphaera aphanis isolates to DMI fungicides: distribution and reduced cross-sensitivity. Pest Manage. Sci. 66:35-43. 
29. Sombardier, A., Savary, S., Blancard, D., Jolivet, J., and Willocquet, L. 2009. Effects of leaf surfaces and temperature on monocyclic processes in Podosphaera aphanis causing powdery mildew of strawberry. Can. J. Plant Pathol. 31:439-448.

30. Spencer, D. M. 1978. The Powdery Mildew Academic Press, New York.

31. Willocquet, L., Sombardier, A., Blancard, D., Jolivet, J., and Savary, S. 2008. Spore dispersal and disease gradients in strawberry powdery mildew.
Can. J. Plant Pathol. 30:434-441.

32. Xiao C. L., Chandler C. K., Price J. F., Duval J. R., Mertely J. C., and Legard, D. E. 2001. Comparison of epidemics of Botrytis fruit rot and powdery mildew of strawberry in large plastic tunnel and field production systems. Plant Dis. 85:901-909.

33. Xu, X.-M., and Madden, L. V. 2002. Incidence and density relationships of powdery mildew on apple. Phytopathology 92:1005-1014. 